\title{
Advances in exercise rehabilitation for patients with Lower Extremity Peripheral Artery Disease
}

\author{
Marco Ambrosetti \\ Cardiovascular Rehabilitation Unit, Le Terrazze Clinic, Cunardo (VA), Italy
}

\begin{abstract}
Patients with Lower Extremity Peripheral Artery Disease (LEPAD) have been recently identified as target groups for structured Cardiac Prevention and Rehabilitation (CPR) programs, whose core components and intervention goals are now well recognized. Historically, exercise training (ET) programs have been employed for the treatment of LEPAD with typical intermittent claudication, and several meta-analysis documented improvements in walking distances of enrolled patients. Both in American and European guidelines, a frequency of at least 3 sessions per week and program duration of 12 weeks were judged as optimal, while recommended sessions lengths were $30-45$ minutes and 30 60 minutes respectively. Among emerging aspects in the field of LEPAD rehabilitation, 1) the extended role of CPR programs in stages other than that of intermittent claudication, 2) an updated identification of predictors of poor outcome after ET, 3 ) the attributable effect of exercise on global cardio-respiratory fitness in LEPAD, 4) the combination of ET and invasive measures for advanced stages of LEPAD, and 5) the role of community walking programs have been discussed.
\end{abstract}

\section{Introduction}

Lower Extremity Peripheral Artery Disease (LEPAD) is a chronic condition characterized by atherosclerotic occlusion or stenosis of the lumen of peripheral arteries, which leads to a reduction in blood flow to the limbs. Prevalence and incidence of LEPAD vary according to selected population and different diagnostic tools. Large European population studies estimated a prevalence of $18 \%$ among subjects aged $>60$

Corresponding author: Marco Ambrosetti, Cardiovascular Rehabilitation Unit, Le Terrazze Clinic, Via U. Foscolo 6/b, 21035 Cunardo (VA), Italy. Tel. +39.0332.992448 - Fax +39.0332.990074.

E-mail:m.ambrosetti@clinicaleterrazze.com

Key words: Peripheral arterial disease; rehabilitation; exercise.

Received for publication: 02 April 2016

Accepted for publication: 29 June 2016

(C) Copyright M. Ambrosetti, 2016

Tipografia PI-ME Editrice, Italy

Monaldi Archives for Chest Disease Cardiac Series 2016; 86:752

doi: 10.4081/monaldi.2016.752

This article is distributed under the terms of the Creative Commons Attribution Noncommercial License (by-nc 4.0) which permits any noncommercial use, distribution, and reproduction in any medium, provided the original author(s) and source are credited. yrs, with about one third of patients being symptomatic [1]. The incidence in women was around half that in men and this gap seems to be reduced at older ages [2].

Risk factors for LEPAD are similar to those of other atherosclerotic disease, particularly coronary artery disease, with the strongest attributable risk for smoking and diabetes mellitus.

In the REACH registry [3], the rate of myocardial infarction, stroke and vascular-related death in the presence of LEPAD was around $15 \%$ over a three-year period, thus confirming the increased risk of cardiovascular events among LEPAD patients.

The most typical and disabling symptom in LEPAD is intermittent claudication, which is defined as pain in the thighs, buttocks or calves, increasing with walking and promptly relieved by rest. Although this is called 'typical claudication', most patients with peripheral artery disease do not have these symptoms and often present with atypical painful legs. Both typical and atypical symptoms may require a rehabilitative approach.

LEPAD is usually categorized according to the Fontaine and/or Rutherford's classification (Table 1), the latter being more commonly cited in newer publications in the field of vascular medicine.

Rehabilitation is a recommended first-line therapy for LEPAD and consists of a comprehensive approach based on clinical stabilization, supervised exercise training (SET), and multidisciplinary counseling. The aim of structured Cardiovascular Prevention and Rehabilitation (CPR) programs in patients with LEPAD is to improve both walking capacity (in case of walking disability) and global functional status, as far as to implement individualized secondary prevention measures to reduce the risk of subsequent cardiovascular events.

\section{Exercise training in peripheral arterial disease: historical perspective}

Historically, exercise training (ET) has been employed for the treatment of LEPAD patients with typical intermittent claudication, based on a large amount of small, often not randomized clinical studies. In the year 1995, Gardner et al. performed a landmark meta-analysis on the efficacy of ET and found improvements of both initial claudication distances (or similarly, time to onset of claudication pain) and absolute claudication distances (or maximal walking time) by $179 \%$ and $122 \%$ respectively [4]. This work also established predictive variables of favourable outcome, thus giving recommendations about the preferred components of ET programs to treat intermittent claudication, i.e. 1) time duration of the single session more than 30 minutes; 2 ) frequency of sessions 3 times/week; and 3) a program duration of at least 6 months. Positive effects of ET were then confirmed by further meta-analysis carried out by Girolami et al. [5] and several Cochrane reviews. In details, the last 2014 Cochrane review [6] considered 30 clinical trials and a global sample size of 1,816 patients randomized to usual care, SET, or placebo: as compared to usual care, SET showed to increase initial claudication distances with an average of 82.3 meters 
Table 1. Clinical staging of LEPAD.

FONTAINE's classification

RUNHERFORD's classification

\begin{tabular}{|c|c|c|c|c|c|}
\hline Stage & \multicolumn{2}{|c|}{ Symptoms } & Symptoms & Grade & Category \\
\hline 1 & Asymptomatic & - & Asymptomatic & 0 & 0 \\
\hline $2 \mathrm{~A}$ & Mild claudication & Absolute claudication distance $>200 \mathrm{~m}$ & Mild claudication & I & 1 \\
\hline \multirow[t]{2}{*}{$2 B$} & \multirow[t]{2}{*}{ Moderate to severe claudication } & Absolute claudication distance $100-200 \mathrm{~m}$ & Moderate claudication & I & 2 \\
\hline & & Absolute claudication distance $<100 \mathrm{~m}$ & Severe claudication & $\mathrm{I}$ & 3 \\
\hline 3 & Ischaemic rest pain & & Ischaemic rest pain & II & 4 \\
\hline \multirow[t]{2}{*}{4} & \multirow[t]{2}{*}{ Ulceration or gangrene } & Necrosis & Minor tissue loss & III & 5 \\
\hline & & Gangrene & Major tissue loss & III & 6 \\
\hline
\end{tabular}

(range 71.9-92.7), as far as absolute claudication distances by 108.9 meters (range 38.2-179.8); walking improvements seemed to be maintained in the following two year after intervention, being not significantly correlated to variations of the ankle brachial index. Unfortunately, no clear evidence about the role of SET in preventing major adverse cardiovascular events in LEPAD patients was obtained. The potential effects of ET on LEPAD-related functional impairment are summarized in Table 2.

SET in LEPAD has been documented as safe, and a recent review [7] of about 3000 patients - globally evaluating more than 80,000 training hours - found a 1:10,340 pts/h rate of major complications.
Based on current evidence, ET was included among therapeutic strategies recommended by international guidelines for the conservative management of LEPAD patients. Both in American and European guidelines [8,9], a frequency of at least 3 sessions per week and a program duration of 12 weeks were judged as optimal, while recommended sessions lengths were 30-45 minutes and 30-60 minutes respectively. However, despite the well-recognized role of ET - and, in a larger perspective, of multi-comprehensive rehabilitation - for vascular conditions, only recently patients with LEPAD were formally considered as target groups for CPR programs in Europe [10], with disease-specific core components (Table 3 ) and goals (Table 4) of intervention.

Table 2. Effects of exercise on functional impairment in LEPAD patients.

\begin{tabular}{ll} 
Pathophysiological mechanism & Effect of exercise \\
Reduced blood flow & $\bullet$ Favourable blood redistribution among different muscle groups \\
& $\bullet$ Neoangiogenesis \\
\hline Endotelial dysfunction & $\bullet$ Improved rheological characteristics of blood flow \\
\hline Skeletal muscles alterations and mitochondrial dysfunction & $\bullet$ Improved nitric oxide-dependent vasodilation \\
\hline Inflammatory activation & $\bullet$ Impaired oxygen utilization by ischemic muscle \\
\hline Atherosclerotic progression & $\bullet$ Ischemic preconditioning \\
& $\bullet$ Impaired carnitine metabolism \\
\hline & $\bullet$ Decreased markers of systemic inflammation \\
\hline
\end{tabular}

Table 3. Core components of cardiovascular rehabilitation in LEPAD patients.

\begin{tabular}{ll} 
Core component & Intervention \\
Patient evaluation & - Any history of walking impairment (i.e., fatigue, aching, numbness, or pain) \\
& - Site of discomfort: buttock, thigh, calf, or foot \\
& - Evaluation of wounds \\
& - Correlation between pain and leg positions \\
& - Evaluation of muscle masses strength and endurance \\
& - Palpation of peripheral pulses \\
& - Ankle-Brachial Index measurement \\
& - Screening for coronary artery disease and aneurismatic lesions \\
\hline Exercise training & - Supervised \\
& - Exercise-rest-exercise modality, coupled with warm-up and cool-down periods \\
& - Treadmill exercise preferred \\
& - Complementary resistance training to be considered \\
\hline - Diet/nutritional counselling \\
- Smoking cessation \\
- Psychosocial management
\end{tabular}


Table 4. Goals of rehabilitative intervention in LEPAD patients.

\begin{tabular}{|c|c|c|c|}
\hline Intervention & Target [Ref] & $\begin{array}{l}\text { Class of recommendation / } \\
\text { Level of evidence [Ref] }\end{array}$ & Remarks \\
\hline $\begin{array}{l}\text { Smoking } \\
\text { cessation }\end{array}$ & Absolute cessation & I/B [9] & $\begin{array}{l}\text { Need for structured counselling. } \\
\text { Drugs such as Varenicline or Bupropion to be considered. } \\
\text { Fagerstrom's test to be considered. }\end{array}$ \\
\hline $\begin{array}{l}\text { Treatment of } \\
\text { blood lipids }\end{array}$ & $\begin{array}{l}\text { LDL-C }<100 \mathrm{mg} / \mathrm{dl} \text { (ideally } \\
<70 \mathrm{mg} / \mathrm{dl} \text { ) or, if not possible, } \\
\geq 50 \% \text { reduction }\end{array}$ & $\mathrm{I} / \mathrm{C}[9]$ & $\begin{array}{l}\text { Statins preferred. Combination therapy or monotherapy } \\
\text { with Ezetimibe could be considered. }\end{array}$ \\
\hline $\begin{array}{l}\text { Antithrombotic } \\
\text { therapy }\end{array}$ & Utilization of antiaggregants & $\mathrm{I} / \mathrm{C}[9] ; \mathrm{I} / \mathrm{A}[18]$ & $\begin{array}{l}\text { ASA } 75-100 \text { mg OD or Clopidogrel } 75 \text { mg OD. } \\
\text { Combination therapy with ASA/Clopidogrel in patients } \\
\text { with under the knee grafts [18]. } \\
\text { Combination therapy with ASA/Clopidogrel in patients } \\
\text { with high thrombotic risk and low risk of bleeding [8]. } \\
\text { Anticoagulants not recommended. }\end{array}$ \\
\hline $\begin{array}{l}\text { Treatment of } \\
\text { blood pressure }\end{array}$ & $\mathrm{BP} \leq 140 / 90 \mathrm{mmHg}$ & $\mathrm{I} / \mathrm{A}[9]$ & $\begin{array}{l}\text { BP target } \leq 130 / 80 \text { in diabetics and patients with chronic } \\
\text { kidney disease questionable. } \\
\text { ACE-Is and ARBs preferred for the reduction of global } \\
\text { cardiovascular risk. } \\
\text { Beta blockers not contraindicated. }\end{array}$ \\
\hline $\begin{array}{l}\text { Treatment } \\
\text { for diabetes }\end{array}$ & HbAlc $\leq 6.5 \%[5][8]$ or $\leq 7 \%$ & $\mathrm{I} / \mathrm{C}[9] ; \mathrm{IIa} / \mathrm{C}[8]$ & 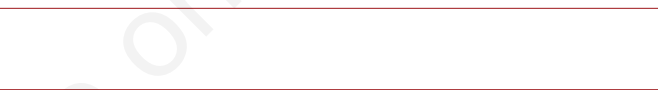 \\
\hline
\end{tabular}

Whatever the exercise-based rehabilitation protocol, patient-reported status evaluation (defined as patient's perceived physical, emotional, and social well-being and function) is also important to assess LEPAD severity and treatment's results. A number of validated general and PAD-specific tools exist; the most commonly used being the Medical Outcomes Study Short Form 36-item (SF-36) questionnaire and the Walking Impairment Questionnaire (WIQ). Other validated disease-specific questionnaires have been used in LEPAD patients, such as the Peripheral Artery Questionnaire, the Vascular Quality of Life questionnaire, the Claudication Scale and the Intermittent Claudication Questionnaire. A recent review [11] assessing the quality of available patient reported outcome measures for intermittent claudication indicated that the PAD quality of life questionnaire (PADQOL), the Intermittent claudication questionnaire (ICQ) and the Vascular quality of life questionnaire (VascuQol) might be appropriate for health related quality of life, while the Walking impairment questionnaire (WIQ) and the Estimate ambulation capacity by history questionnaire (EACH-Q) appear suitable for functional status.

\section{What is new for LEPAD rehabilitation?}

Several emerging aspects could be considered in the field of LEPAD rehabilitation. Firstly, the extended role of CPR programs not only for the stage of intermittent claudication, but for LEPAD condition at all. This was derived from the belief that advanced stages of LEPAD are also source of disability and impaired quality of life, with a strong need for clinical stabilization and slowdown of hemodynamic deterioration. For these purposes, endurance and resistance training modalities for LEPAD patients without intermittent claudication are summarized in Table 5.

Secondly, better definition of several patient characteristics and comorbid conditions that may lead to poorer treatment outcomes of SET has been reached. This topic was recently updated in a large population of patients with intermittent claudication $(n=2995)$ that followed SET in the usual care setting [12], by investigating the association between age, gender, BMI, smoking behavior, orthopedic comorbidity, neurologic comorbidity, cardiac comorbidity, vascular comorbidity, pulmonic

Table 5. Training modalities for LEPAD patients without intermittent claudication.

\begin{tabular}{llll} 
& Endurance training & & \multicolumn{2}{c}{ Resistance training } \\
Frequency & $3-5$ day/week & Frequency & $\geq 2$ day/week \\
\hline Modality of exercise & - Treadmill & Modality of exercise & All major muscle groups \\
& - Stairclimber & \\
& - Cyclette & \\
& - Arm cycle ergometry & \\
& - Rowing & \\
& - Swimming & Intensity & $1-3$ sets of 8-15 RM for each muscle group \\
\hline Intensity & - Resting heart rate $+40-60 \%$ heart rate reserve & \\
\hline Duration & - Resting $\mathrm{VO}_{2}+40-60 \% \mathrm{VO}_{2}$ reserve & & \\
\hline
\end{tabular}


comorbidity, internal comorbidity and initial claudication distance during and after supervised treadmill exercise with a 1-year time horizon. This study showed that female gender, advanced age, a high BMI and cardiac comorbidity are associated with less improvement in initial claudication distances after 1, 3, 6 and 12 months of SET. Females often display less improvement in claudication distances as compared to males after SET, mostly due to more impaired microvascular function and diminished aerobic capacity and elasticity of arteries.

Thirdly, a reappraisal of the attributable effect of exercise on global cardio-respiratory fitness in LEPAD. On this topic, Parmenter et al. [13] recently carried out a systematic review and meta-analysis of 41 RCTs of exercise training versus usual medical care, aimed at exploring benefits elicited via exercise training, both in terms of walking abilities and change in aerobic capacity $\left(\mathrm{VO}_{2}\right.$ peak). In addition to the increase of walking distances, this review showed that exercise training produced significant $\mathrm{VO}_{2}$ peak improvements with mean difference (MD) $0.62 \mathrm{ml} \bullet \operatorname{kg}(-1) \bullet \min (-1)(95 \%$ CI $0.47-0.77 ; \mathrm{p}<0.00001)$. Sub-analysis of $\mathrm{VO}_{2}$ peak according to exercise training pain thresholds also suggested that no-to-mild pain may be superior (MD 0.79 $\mathrm{ml} \bullet \operatorname{kg}(-1) \bullet \min (-1)$ [95\% CI $0.45-1.14, \mathrm{p}<0.00001])$ to moderate-tomaximum training pain (MD $0.49 \mathrm{ml} \bullet \mathrm{kg}(-1) \bullet \min (-1)$ [95\% CI $0.31-$ $0.66, \mathrm{p}<0.00001]$ ). Moreover, $\mathrm{VO}_{2}$ peak improvements were documented by means of arm cranking as well as for lower limb exercise.

Moreover, the exact role of SET as an adjunct to or substitute for intervention in more advanced disease has been recently clarified by a review of 11 randomized studies inclusive of 969 patients [14]. According to literature, in patients requiring intervention (open surgery or endovascular) a combination of surgical intervention and SET offered superior outcomes to monotherapy across multiple studies, particularly for walking distances. Comparison of SET and endovascular revascularization showed similar outcomes for walking ability, however only endovascular measures resulted in significant improvements in ankle-brachial index. Only one study compared open surgery and SET, with a better outcome for the surgical approach. These data strongly support the use of SET as an adjunct to any operative intervention in LEPAD patients. Better functional results in the long-term conferred by adding SET to intervention could be explained by the induced stimulation of collateralization and the release of vasodilators such as nitric oxide, as shown by several studies [15,16].

Finally, the increasingly recognized relevance of community walking programs for treatment of peripheral artery disease, to overcome several implementation barriers such as the limited supply of inhospital programs, the high volume of exercise visits required by outpatients over an extended period of time, and lack of patient motivation. ET programs - generally based on walking - that occur in community settings have recently gained attention in the literature as they potentially bypass many of the barriers associated with SET. A review of community walking programs performed in the year 2013 [17] confirmed that general recommendations for patients to walk at home are not effective to increase walking performance on the treadmill, but conversely, community trials that incorporated more advice and feedback for LEPAD patients resulted in similar outcomes as compared to facility-based SET programs.

\section{Conclusions}

CPR programs might have the possibility to be considered as appropriate and cost-effectiveness interventions to promote clinical stabilization and attenuate disabilities in a variety of LEPAD conditions. Future research should be aimed at identifying best practices for each stage of LEPAD, from asymptomatic to severely ischemic patient, as far as the proper setting of intervention and a recommended strategy to maintain CPR goals in the long term. By now, CPR should be integrated into daily practice for LEPAD, and still inadequate attendance rates of patients to structured programs should be improved.

\section{References}

1. Sigvant B, Wiberg-Hedman K, Bergqvist D, et al. A populationbased study of peripheral arterial disease prevalence with special focus on critical limb ischemia and sex differences. J Vasc Surg 2007; 45:1185-91.

2. Kroger K, Stang A, Kondratieva J, et al. Prevalence of peripheral arterial disease-results of the Heinz Nixdorf recall study. Eur J Epidemiol 2006; 21: 279-85.

3. Alberts MJ, Bhatt DL, Mas JL, et al. Three-year follow-up and event rates in the International REduction of Atherothrombosis for Continued Health Registry. Eur Heart J 2009;30:2318-26.

4. Gardner AW, Poehlman ET. Exercise rehabilitation programs for the treatment of claudication pain: a meta-analysis. JAMA 1995;274: 975-80.

5. Girolami B, Bernardi E, Prins MH, et al. Treatment of intermittent claudication with physical training, smoking cessation, pentoxifylline, or nafronyl: a meta-analysis. Arch Intern Med 1999;159: $37-45$.

6. Lane R, Ellis B, Watson L, Leng GC. Exercise for intermittent claudication. Cochrane Database Syst Rev. 2014:CD000990. DOI: 10.1002/14651858.CD000990.pub3

7. Gommans LN, Fokkenrood HJ, van Dalen HC, et al. Safety of supervised exercise therapy in patients with intermittent claudication. J Vasc Surg 2015;61:512-8.

8. Anderson JL, Halperin JL, Albert N, et al. Management of patients with peripheral artery disease (compilation of 2005 and 2011 ACCF/AHA Guideline Recommendations): a report of the American College of Cardiology Foundation/American Heart Association Task Force on Practice Guidelines. J Am Coll Cardiol 2013;61:1555-70.

9. European Stroke Organisation, Tendera M, Aboyans V, et al. ESC Guidelines on the diagnosis and treatment of peripheral artery diseases: Document covering atherosclerotic disease of extracranial carotid and vertebral, mesenteric, renal, upper and lower extremity arteries: the Task Force on the Diagnosis and Treatment of Peripheral Artery Diseases of the European Society of Cardiology (ESC). Eur Heart J 2011;32:2851-906.

10. Piepoli MF, Corrà U, Benzer W, et al. Secondary prevention through cardiac rehabilitation: from knowledge to implementation. A position paper from the Cardiac Rehabilitation Section of the European Association of Cardiovascular Prevention and Rehabilitation. Eur J Cardiovasc Prev Rehab 2010;17:1-17.

11. Conijn AP, Jens S, Terwee CB, et al. Assessing the quality of available patient reported outcome measures for intermittent claudication: a systematic review using the COSMIN checklist. Eur J Vasc Endovasc Surg 2015;49:316-34.

12. Gardner AW, Montgomery PS, Blevins SM, et al. Gender and ethnic differences in arterial compliance in patients with intermittent claudication. J Vasc Surg 2010;51:610-15.

13. Parmenter BJ, Dieberg G, Smart NA. Exercise training for management of peripheral arterial disease: a systematic review and meta-analysis. Sports Med 2015;45:231-44.

14. Aherne T, McHugh S, Kheirelseid EA, et al. Comparing supervised exercise therapy to invasive measures in the management 
of symptomatic peripheral arterial disease. Surg Res Pract 2015; 2015:960402.

15. McDermott MM, Carroll TJ, Kibbe M, et al. Proximal superficial femoral artery occlusion, collateral vessels, and walking performance in peripheral artery disease. JACC Cardiovasc Imaging 2013; 6:687-94.
16. Allen JD, Stabler T, Kenjale A, et al. Plasma nitrite flux predicts exercise performance in peripheral arterial disease after 3 months of exercise training. Free Radical Bio Med 2010;49:1138-44.

17. Mays RJ, Rogers RK, Hiatt WR, et al. Community walking programs for treatment of peripheral artery disease. J Vasc Surg 2013; 58:1678-87. 